\title{
АИНАМИЧЕСКАЯ КОНТРАСТНАЯ МАГНИТНО-РЕЗОНАНСНАЯ ТОМОГРАФИЯ СКЕАЕТНЫХ МЫШЦ У ПАЦИЕНТОВ С ХРОНИЧЕСКОЙ ИШЕМИЕЙ НИЖНИХ КОНЕЧНОСТЕЙ
}

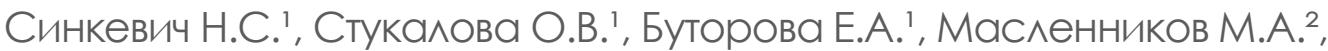 \\ Талицкий К.А' ., Булкина О.С. ${ }^{\prime}$, Карпов Ю.А. ${ }^{1}$, Терновой С.К. ${ }^{1,3}$
}

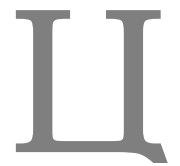

ель исследования. Изучить возможности динамической контрастной магнитно-резонансной томографии (МРТ) в оценке перфузии скелетных мышц у пациентов с хронической ишемией нижних конечностей (ХИНК) в сравнении с пациентами без ХИНК и здоровыми добровольцами.

Материалы и методы. В исследование включено 56 пациентов, из них 35 пациентов с ХИНК со средним модыжечно-плечевым индексом давления ( $\Lambda П И) ~ 0,6 \pm 0,17,13$ пациентов с ишемической болезнью сердца (ИБС) с нормальным $\Lambda$ ПИ и 8 здоровых добровоцьцев. Испытуемые выполняли плантарную фмексию в положении мёжа на спине в томографе с напряженностью магнитного поля 1,5 ТА в течение 5 минут или до появления Аимитирующих симптомов. Проводимось измерение пиковой интенсивности мышечной перфузии (МП), времени достижения пиковой МП и пиковой интенсивности артериального кровотока.

Результаты. Пиковая МП в покое и при нагрузке в группе контроля достоверно выше, чем у пациентов с ХИНК ( $\mathrm{p}=0,0045, \mathrm{p}=0,0003$ соответственно). В подгруппе здоровых добровольцев не наблюдалось значимого увеличения МП при нагрузке, в отличие от группы ХИНК и ИБС ( $\mathrm{p}=0,0012, \mathrm{p}=0,0001$ соответственно). Пиковая интенсивность кровотока при нагрузке в группе пациентов без ХИНК достигалась достоверно быстрее, чем в покое $(\mathrm{p}=0,013)$, тогда как в группе ХИНК оставалась неизменной.

Выводы. Динамическая контрастная МРТ - перспективный неинвазивный метод, при помощи которого возможно выявить изменение мышечной перфузии в ответ на нагрузку у пациентов с хронической ишемией нижних конечностей, что позволяет косвенно судить о степени выраженности комлатерального кровообращения. Метод может быть использован дмя оценки эффективности различных видов консервативной терапии, направленных на стимуляцию роста и/или развития комлатеральных сосудов в ишемизированной мышце.

КАючевые слова: динамическая контрастная МРТ, хроническая ишемия нижних конечностей, мышечная перфузия, артериальный кровоток, модыжечно-плечевой индекс давцения.

\section{DYNAMIC CONTRAST-ENHANCED MRI IN PATIENTS WITH PERIPHERAL ARTERY DISEASE}

\section{Sinkevich N.S. ', Stukalova O.V. ', Butorova E.A. ', Maslennikov M.A. ${ }^{2}$, Talitskiy K.A. ${ }^{1}$, Bulkina O.S. ', , Karpov YU.A. ${ }^{1}$, Ternovoy S.K. ${ }^{1}, 3$}

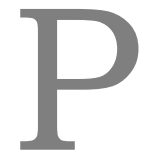

urpose. Explore the possibilities of a dynamic contrast magnetic resonance imaging for skeletal muscle perfusion evaluation in patients with chronic lower limb ischemia compared with control group.

Materials and methods. A total of 56 subjects were studied, from which 35 patients with peripheral arterial disease (PAD) and a mean ankle-brachial index (ABI) $0.6 \pm 0.17$ and a control group of 21 (13 age-matched patients with ischemic heart disease (IHD) with normal $\mathrm{ABI}$ and 8 healthy volunteers). All examined participants performed supine plantar flexion exercise in a $1.5 \mathrm{~T}$ MRI scanner for 5 minutes or until limiting symptoms with intravenous

\section{1 - Институт} кардиологии им. А.А. Мясникова ФГБУ «Российский кардиологический научнопроизводственный комплекс".

2 - ГБУ ГКБ №1 им. Н.И. Пирогова ДЗМ. 3 - ГБОУ ВПО «Первый МГМУ им. И.М. Сеченова".

г. Москва, Россия

1 - Russian Cardiology Research Center. 2 - N.I. Pirogov First City Clinical Hospital. 3 - I.M. Sechenov First Moscow State Medical University.

Moscow, Russia. 


\section{RUSSIAN ELECTRONIC JOURNAL OF RADIOLOGY}

gadolinium-based contrast media administration (GdDPA). Peak tissue perfusion (TP), timeto-peak TP and time-to-peak arterial input flow (AIF) were measured.

Results. Peak rest TP of 21 controls was significantly higher than in PAD patients $(p=0.0045)$, as well as peak exercise TP $(p=0.0003)$. Intergroup analysis showed no postexercise TP increase in healthy volunteers $(p=0.06)$, at the opposite there was a significantly post-exercise peak TP increase in PAD patients $(p=0.0012)$ and IHD controls $(p=0.0001)$. Post-exercise time-to-peak AIF in PAD patients didn't differ from the rest one, whereas in controls it was significantly lower $(p=0.013)$. No contrast-related complications were matched.

Conclusions. Contrast-enhanced MRI is safe and effective method for skeletal muscle perfusion evaluation which strongly distinguishes PAD patients from those with normal limb flow. This method may be useful in a PAD treatment evaluation, sport medicine and experimental research.

Keywords: contrast-enhanced MRI, peripheral artery disease, tissue perfusion, arterial input flow, ankle-brachial index.

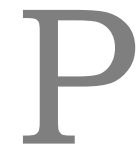

аспространенность

стенозирующего атеросклероза артерий нижних конечностей в общей популяции по данным ряда эпидемиологических исследований составмяет от $3 \%$ до $10 \%$, возрастая до 15-20\% в группе пациентов старше 70 мет [1, 2]. Расчетная ежегодная частота развития критической ишемии нижних конечностей варьирует от 500 до 1000 случаев на 1 мимлион насемения [3].

Диагностика хронической ишемии нижних конечностей на основании ведущего кАинического симптома - перемежающейся хромоты - обычно не представцяет трудностей, однако зачастую заболевание протекает в матентной форме или проявляется атипичной симптоматикой, что требует применения инструментальных методов диагностики [4]. По данным Edinburgh Artery Study из более, чем 1500 пациентов симптомы перемежающейся хромоты присутствовали мишь у 4,5\%, в 8\% случаев выявлялись значимые нарушения кровотока при отсутствии кАинической симптоматики, более 16\% пациентов имели отклонения от нормы по данным инструментальных методов исследования [5]. В крупном исследовании PARTNERS бымо обследовано окомо 7000 человек (пациенты старше 70 мет, а также мица в возрасте 5069 мет с факторами риска развития атероскцероза). Поражение периферических артерий бымо диагностировано у 29\% обследованных, при-

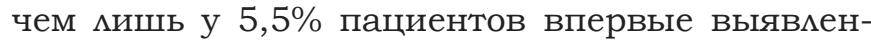
ное заболевание сопровождалось классической клинической картиной перемежающейся хромоты [6]. Похожие данные были получены и в некоторых других крупных эпидемиологических исследованиях [7].

По данным Межобщественного согласительного документа по ведению пациентов с заболеванием периферических артерий (TASC II) y 5-10\% пациентов с бессимптомным ими малосимптомным течением хронической ишемии нижних конечностей (ХИНК) в течение пяти мет развивается кминическая картина критической ишемии нижних конечностей (III-IV стадии по классификации Фонтейна) [8]. Учитывая частое несовпадение клинической картины заболевания со степенью его тяжести, возникают сложности в ранней диагностике облитерирующего атеросклероза артерий нижних конечностей.

Измерение модыжечно-плечевого индекса давления (АПИД) - широко применяемый в рутинной практике метод как дмя диагностики, так и дмя оценки эффективности мечения ХИНК, однако, у пациентов с выраженным кальцинозом артериальной стенки (например, при сахарном диабете, сердечной недостаточности) его использование нецелесообразно. Дупмексное сканирование периферических артерий и мультиспиральная компьютерная томография с контрастированием - современные методы, позволяющие оценить степень и мокализацию стенотического поражения, но с их помощью трудно оценить эффективность консервативной терапии пациентов с ХИНК, ввиду небольших изменений на макрососудистом уровне ими их отсутствия. Вышеобозначенные методы не дают представцения о мышечной перфузии, исследование которой могмо бы помочь в неинвазивной оценке динамики состояния пациентов с ХИНК и результатов консервативного $е$ чения.

В настоящее время доступен ряд методов, позволяющих судить о степени мышечной перфузии. Магнитно-резонансная томография давно используется дмя исследования различных органов, в том числе сердца и сосудов [9]. Исследование перфузии ткани методом магнитно-резонансной томографии - перспективный диагностический метод, основанный на 


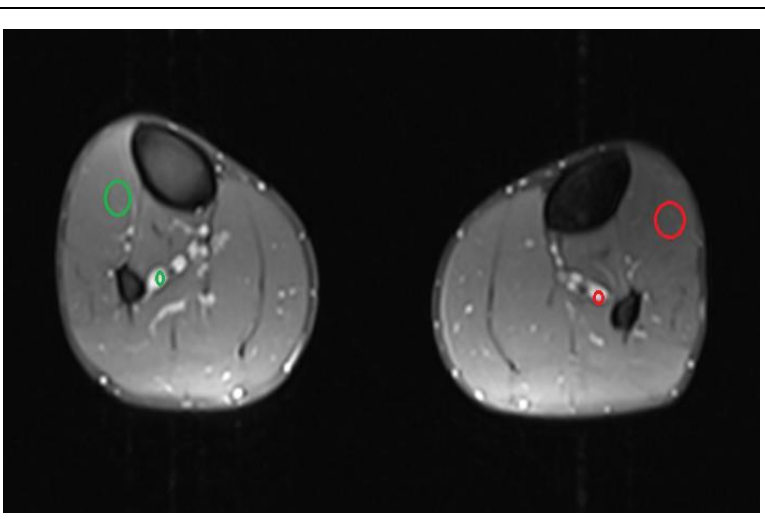

Рис. 1,a.

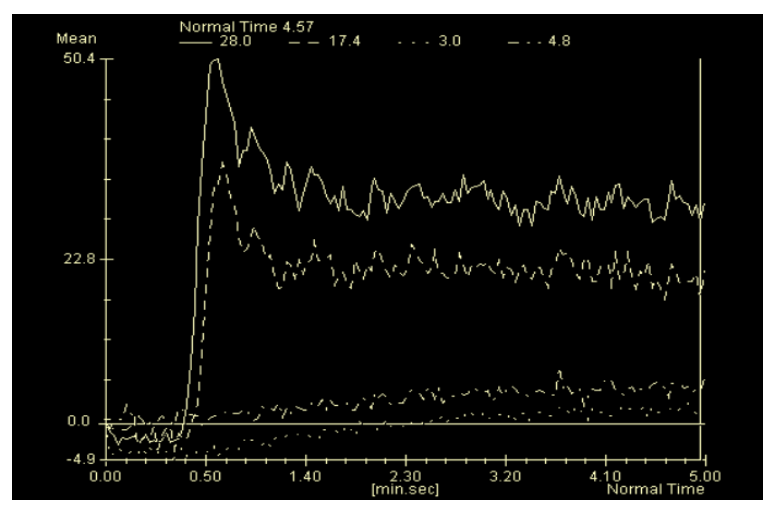

Рис. 1,6.

\section{Рис. 1. Аинамическая контрастная МРТ. Обработка Аанных.}

а - Определение области интереса. б - Кривые интенсивности сигнала: верхние кривые с ранним пиком соответствуют интенсивности кровотока, нижние - пологие - тканевой перфузии в покое.

получении серии изображений на фоне введения контрастного препарата, не проникающего через цитоплазматическую мембрану во внутриклеточное пространство (гадолиния диэтилпентаацетата (GdDTPA)) с последующим исследованием кинетики его накопления и выведения [10].

В серии исследований показана способность метода отмичать пациентов с ХИНК от группы контроля на основании оценки показателей перфузии мышц нижних конечностей в покое и при нагрузке [11 - 16].

Материалы и методы.

В исследование были включены 35 пациентов с хронической ишемией нижних конечностей (II-III стадии по классификации Фонтейна-Покровского) в возрасте от 47 до 76 мет (группа I), 13 пациентов с ишемической болезнью сердца (ИБС) без признаков ишемии конечностей в возрасте от 32 до 67 мет (группа II) и 8 здоровых добровольцев в возрасте от 24 до 51 года (группа III).

В группу пациентов с ХИНК вкАючались мужчины и женщины с хронической ишемией нижних конечностей атеросклеротического генеза II-III стадии и клинической картиной перемежающейся хромоты. Критериями исключения являлись перенесенное менее чем за 6 месяцев острое сердечно-сосудистое событие, критическая ишемия нижних конечностей, наличие обширных трофических дефектов кожи и мягких тканей, тяжелая почечная недостаточность со скоростью киубочковой фимьтрации менее 30 м^/мин, декомпенсированная хроническая сердечная недостаточность, онкомогические заболевания в анамнезе, а также наличие общих противопоказаний к проведению магнитно-резонансной томографии. Все пациенты проходими стационарное мечение на базе отдема ангиологии Института Кцинической
Кардиологии имени А.. Мясникова ФГБУ РКНПК МЗ РФ. Помимо стандартного цечения, направценного на коррекцию модифицируемых факторов риска (антиангинальная, гипотензивная, мипидснижающая, антиагрегантная терапия), пациентам проводицся курс инфузионной терапии синтетическими аналогами простагландина Е1 (алпростадиц 60-100 мкг/сут), а также сеансы тренировочной ходьбы на тредмиме.

Группа испытуемых с ишемической бомезнью сердца без ХИНК также состояла из пациентов указанного отдемения, находившихся на плановой госпитализации по поводу основного заболевания. Все пациенты получали необходимую антиангинальную, гипотензивную, антиагрегантную и гиполипидемическую терапию, части из них впоследствии была выполнена коронарная ангиопластика со стентированием. Перед включением в исследование проводимась оценка клинического состояния путем опроса, измерение модыжечно-плечевого индекса давцения и проведение теста шестиминутной ходьбы. Пациенты, предъявмяющие жалобы на боли в нижних конечностях при ходьбе и/или

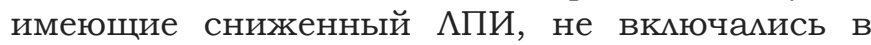
исследование и направлялись на дообследование.

\section{Протокол МРТ.}

Исследование перфузии мышц голеней выполнялось на MР-томографе "Magnetom Avanto", 1,5 Тム (Siemens AG, Germany) с испоцьзованием поверхностной радиочастотной катушки для тела. Пациенты располагались в канале томографа в положении межа на спине ногами вперед, катушка центрировалась на уровне максимального объема голени. Стандартный протокол исследования включал в себя 2 фазы: исследование перфузии в покое и при нагрузке. Исследование в покое вк^ючало в се- 
Таблица №1. Сравнитемьная характеристика испытуемых.

\begin{tabular}{|c|c|c|c|}
\hline Характеристика & $\begin{array}{c}\text { Группа I } \\
\text { (ХИНК), } n=35\end{array}$ & $\begin{array}{c}\text { Группа II (ИБС без } \\
\text { ХИНК), n=13 }\end{array}$ & $\begin{array}{c}\text { Группа III (здоровые добро- } \\
\text { вольцы),n=8 }\end{array}$ \\
\hline Возраст, лет & $61 \pm 8$ & $57 \pm 11^{*}$ & $40 \pm 10$ \\
\hline Женский пол, n & $3(8,5 \%)$ & $3(23 \%)$ & $2(25 \%)^{*}$ \\
\hline $\begin{array}{c}\text { Лодыжечно-плечевой индекс } \\
\text { давления }\end{array}$ & $0,6 \pm 0,17$ & $1 \pm 0,1$ & $1 \pm 0,1$ \\
\hline Курение, n & $18(51 \%)$ & $4(28 \%)^{*}$ & $2(25 \%)^{*}$ \\
\hline Анамнез курения, $n$ & $14(40 \%)$ & $4(30 \%)^{*}$ & $2(25 \%)^{*}$ \\
\hline $\begin{array}{c}\text { Ишемическая болезнь серд- } \\
\text { ца, } n\end{array}$ & $28(80 \%)$ & $13(100 \%)^{*}$ & 0 \\
\hline Артериальная гипертония, $n$ & $33(93 \%)$ & $13(100 \%)^{*}$ & 0 \\
\hline Сахарный диабет, n & $8(23 \%)$ & $2(15 \%)^{*}$ & 0 \\
\hline $\begin{array}{c}\text { Стентирование нижних ко- } \\
\text { нечностей, } \mathrm{n}\end{array}$ & $4(12 \%)$ & 0 & 0 \\
\hline $\begin{array}{l}\text { Шунтирование нижних ко- } \\
\text { нечностей, } \mathrm{n}\end{array}$ & $4(12 \%)$ & 0 & 0 \\
\hline
\end{tabular}

бя топограмму (последовательность TrueFISP, по 3 среза в 2-х плоскостях, поперечной и фронтальной), серию изображений в корональной проекции (T2-trufi) и перфузионное исследование мышц с использованием последовательности TurboFLASH. Контрастный препарат на основе GdDTPA вводился внутривенно болюсно при помощи автоматического инжектора "Optistar" со скоростью 3 мл/с в стандартной дозе $(0,1$ ммоль/кг). Одновременно происходило сканирование на 5 уровнях в поперечной плоскости. Исследование перфузии во время нагрузки, вторая фаза, проводилось по той же схеме после фмексии/экстензии стоп в положе-

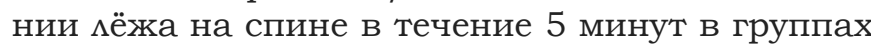
II - III и до появления мимитирующих симптомов ишемии в группе I (в среднем 90 секунд).

Анализ данных.

Данные обрабатывались при помощи программы Siemens Mean Curve. На основании визуализации максимального контрастирования передней большеберцовой или других артерий голени (в случае окклюзии первой) и сигнала, полученного от передней большеберцовой мышцы путем установки области интереса в её проекции, были построены кривые интенсивности сигнала. Оценивались следующие показатеми: пиковая мышечная перфузия (МП) в покое и после нагрузки (пок/нагр), время достижения пиковой интенсивности кровотока и перфузии в покое и при нагрузке.

В группе контроля и нормы анализировамись показатели по правой нижней конечности, в группе пациентов с ХИНК - данные симптомной конечности.

На рисунке 1 представцен процесс обработки полученных данных. Верхние кривые с ранним пиком соответствуют интенсивности кровотока в покое на правой и мевой конечностях, нижние - помогие - тканевой перфузии в покое.

Статистический анализ.

Основные анализируемые показатели явмяются непрерывными переменными и представлены как среднее значение \pm стандартное откцонение ими медиана [25; 75 процентили]. Все выборки подвергались анализу на нормальность с помощью теста Колмогорова-Смирнова. Анализ групп на сопоставимость проводицся при помощи теста Манна-Уитни и метода табмиц сопряженности 2х2, критерия Фишера. Сравнение между группами выполнялось с использованием непарного t-теста (дия нормального распределения) и теста Манна-Уитни (дия неправицьного распредемения). Статистический анализ выполнялся при помощи программы GraphPad Prism5.

\section{Результаты.}

Сравнительная характеристика испытуемых представлена в таблице №1. Анализируемые группы с ХИНК и без были сопоставимы по основным характеристикам.

Согласно полученным данным, пиковая интенсивность мышечной перфузии (МП) в покое у пациентов с хронической ишемией конечностей ниже, чем в контрольной группе без ХИНК $(6,34 \pm 2,9$ vs $7,55 \pm 1,38, p=0,0045)$, в том числе при отдельном сравнении с сопоставимой по полу и возрасту группой больных ишемической болезнью сердца $(6,34 \pm 2,9$ vs $7,41 \pm 1,3$, $\mathrm{p}=0,016)$.

После выполнения предможенной нагрузки также были выявлены значимые различия по показателю пиковой интенсивности перфузии между группами $(8,13 \pm 2,3$ vs $11,88 \pm 3,83$, 
Табицца №2. Сравнение иссиедуемых показатемей в основных группах.

\begin{tabular}{|c|c|c|c|c|c|c|}
\hline & & $\begin{array}{l}\text { Пациенты с } \\
\text { ХИНК, } \mathrm{n}=35\end{array}$ & $\begin{array}{c}\text { Пациенты } \\
\text { без ХИНК, } \\
\text { n=21 }\end{array}$ & $\begin{array}{c}\text { Пациенты с } \\
\text { ИБС, } n=13\end{array}$ & $\begin{array}{l}\text { Здоровые доб- } \\
\text { ровольцы, n=8 }\end{array}$ & $\mathrm{p}<\mathbf{0 , 0 5}$ \\
\hline & & 1 & 2 & 3 & 4 & \\
\hline $\begin{array}{c}\text { МП макс.* по- } \\
\text { кой }\end{array}$ & $\mathbf{a}$ & $6,34 \pm 2,9$ & $7,55 \pm 1,38$ & $7,41 \pm 1,3$ & $7,78 \pm 1,59$ & $\begin{array}{c}1 \mathrm{a}-2 \mathrm{a}, \\
\begin{array}{c}1 \mathrm{a}-3 \mathrm{a}, 1 \mathrm{a}-4 \mathrm{a}, 1 \mathrm{a}-16,2 \mathrm{a}- \\
26,3 \mathrm{a}-36\end{array}\end{array}$ \\
\hline $\begin{array}{l}\text { МП макс. } \\
\text { нагрузка }\end{array}$ & б & $8,13 \pm 2,3$ & $11,88 \pm 3,83$ & $12,22 \pm 3,34$ & $11,32 \pm 4,7$ & 1б-2б, 1б-зб,1б-4б \\
\hline $\begin{array}{l}\text { Время достиже- } \\
\text { ния АК макс.** } \\
\text { в покое, с }\end{array}$ & B & $38,66 \pm 6,62$ & $40,71 \pm 9,91$ & $41,54 \pm 10,28$ & $39,38 \pm 9,78$ & $2 \mathrm{~B}-2 \Gamma, 4 \mathrm{~B}-4 \Gamma$ \\
\hline $\begin{array}{c}\text { Время достиже- } \\
\text { ния АК макс. } \\
\text { при нагрузке, с }\end{array}$ & $\Gamma$ & $38,4 \pm 9,9$ & $33,33 \pm 8,27$ & $35,38 \pm 8,53$ & $30,00 \pm 7,07$ & $1 \Gamma-4 \Gamma$ \\
\hline $\begin{array}{l}\text { Время достиже- } \\
\text { ния МП макс. в } \\
\text { покое, с }\end{array}$ & д & $299 \pm 1,56$ & $299 \pm 3$ & $298,5 \pm 3,75$ & 300 & $\begin{array}{c}1 д-1 е, 2 д-2 e, 3 д-3 e, 4 д-~ \\
4 e\end{array}$ \\
\hline $\begin{array}{l}\text { Время достиже- } \\
\text { ния МП макс. } \\
\text { при нагрузке, с }\end{array}$ & e & $38,78 \pm 10,23$ & $35,95 \pm 7,18$ & $37,69 \pm 7,53$ & $33,13 \pm 5,94$ & \\
\hline $\begin{array}{l}\text { Изменение вре- } \\
\text { мени кровотока } \\
\text { (ж) }\end{array}$ & ж & $0[-5 ; 5]$ & $5[2,5 ; 10]$ & $5[2,5 ; 10]$ & $5[2,5 ; 13,75]$ & 1ж-2ж, 1ж-4ж \\
\hline
\end{tabular}

$\mathrm{p}=0,0003$ дмя пациентов с ХИНК и без ХИНК; $8,13 \pm 2,3$ vs $12,22 \pm 3,34, \mathrm{p}<0,0001$ для пациентов с ХИНК и ИБС без ХИНК). Достоверных размичий по показателю пиковой интенсивности МП в покое и при нагрузке между подгруппами пациентов с нормальным кровообращением нижних конечностей (бомьных ИБС и здоровых добровоцьцев) не наблюдамось.

В группе пациентов с перемежающейся хромотой показатель пиковой интенсивности МП значимо увеличивался при нагрузке по сравнению с данными покоя $(8,13 \pm 2,3$ vs $6,34 \pm 2,9, p=0,0012)$. Пиковая интенсивность перфузии при нагрузке увеличивалась по отношению к показателю покоя и в группе пациентов с ИБС $(12,22 \pm 3,34$ vs $7,41 \pm 1,3, p=0,0001)$, тогда как у здоровых добровольцев размичие имело мишь тенденцию $\mathrm{K}$ достоверности $(11,32 \pm 4,7$ vs $7,78 \pm 1,59, \mathrm{p}=0,06)$. Основные результаты исследования представлены в таблице №2.

Кривые интенсивности МП и кровотока здорового добровольца и пациента с перемежающейся хромотой в покое представмены на рисунке 2, при нагрузке - на рисунке 3 .

Время достижения пиковой интенсивности кровотока в покое между группами досто- верно не разцичалось. Однако, было отмечено, что при нагрузке у пациентов с ХИНК пиковая интенсивность кровотока достигалась значительно медиеннее, чем у здоровых добровоцьцев $(38,4 \pm 9,9$ c vs $30,0 \pm 7,07$ c, p=0,0164).

В группе пациентов с ХИНК время достижения пика кровотока не изменялось при нагрузке $(38,66 \pm 6,62$ c vs $38,4 \pm 9,9$ c, p=0,5), тогда как в группе пациентов без ХИНК достоверно уменьшалось $(40,71 \pm 9,91$ c vs 33,33 $\pm 8,27$ $c, p=0,013)$. Среди испытуемых без ишемии конечностей достоверное уменьшение времени достижения пика кровотока при нагрузке отмечалось у здоровых добровольцев $(39,38 \pm 9,78$ с vs $30,0 \pm 7,07 \mathrm{c}, \mathrm{p}=0,04)$, хотя тенденция к более быстрому достижению максимума кровотока наблюдалась и среди пациентов с ИБС $(41,54 \pm 10,28$ c vs $35,38 \pm 8,53$ c, p=0,06).

На фоне физической нагрузки время достижения пиковой интенсивности кровотока у пациентов без ХИНК сократимось на 5 секунд $[2,5 ; 10$ процентили], что достоверно отмичалось от группы ХИНК (p=0,0288), дмя которой показатель при нагрузке не менялся - О[-5; 5 процентили]. Размичия по показателю изменения времени были получены и при сравнении пациен- 


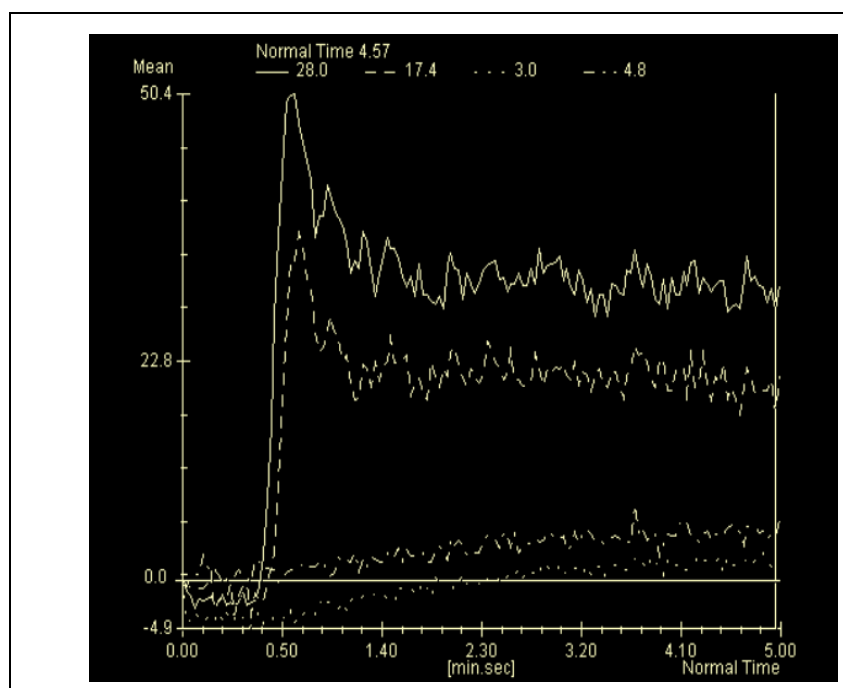

Рис. 2, a.

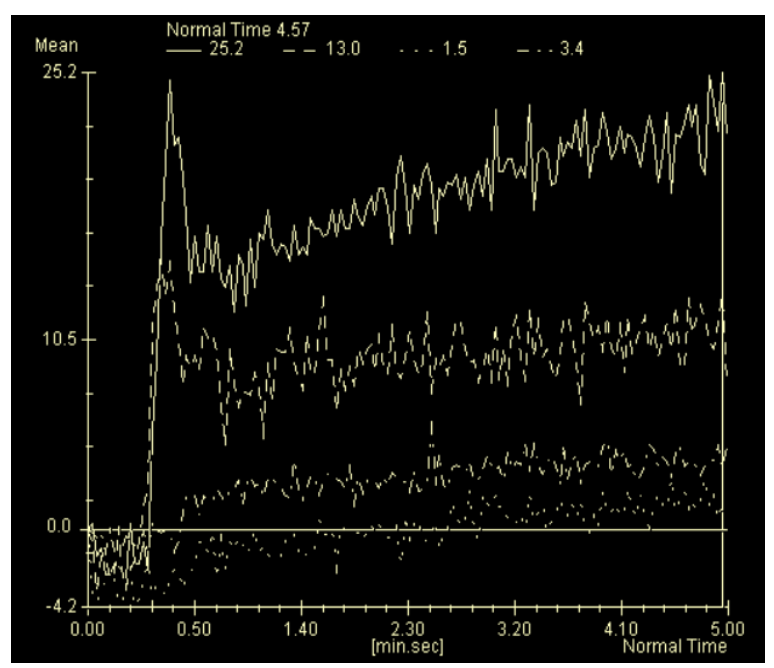

Рис. 2, б.

\section{Рис. 2. Аинамическая контрастная МРТ.}

а - Кривые интенсивности сигнала артериального кровотока и мышечной перфузии зАорового Аобровольца в покое.

б - Кривые интенсивности сигнала артериального кровотока и мышечной пероузии пациента с ХИНК в покое. Абсолютные значения пиковой интенсивности кровотока и перорузии в покое у зАорового Аобровольца выше, чем у пациента с ХИНК.

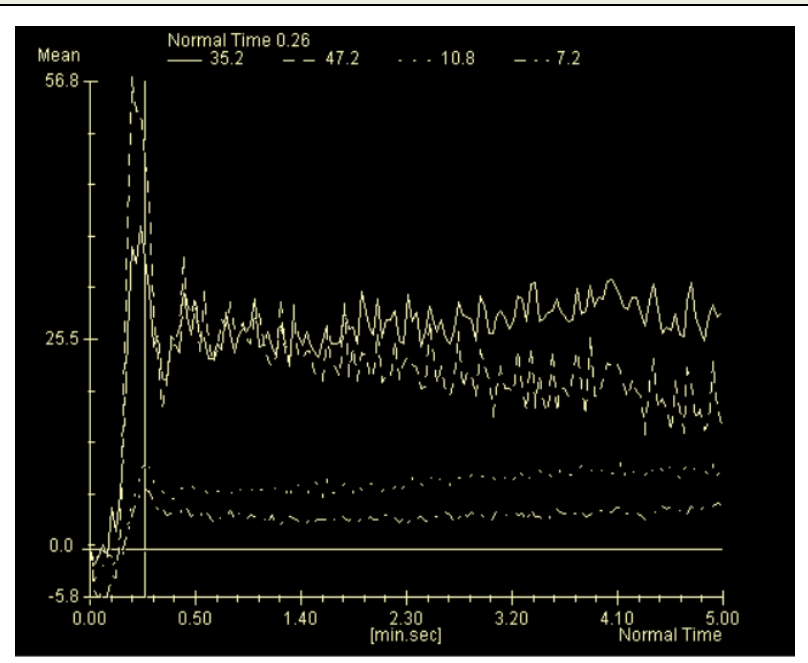

Рис. 3,a.

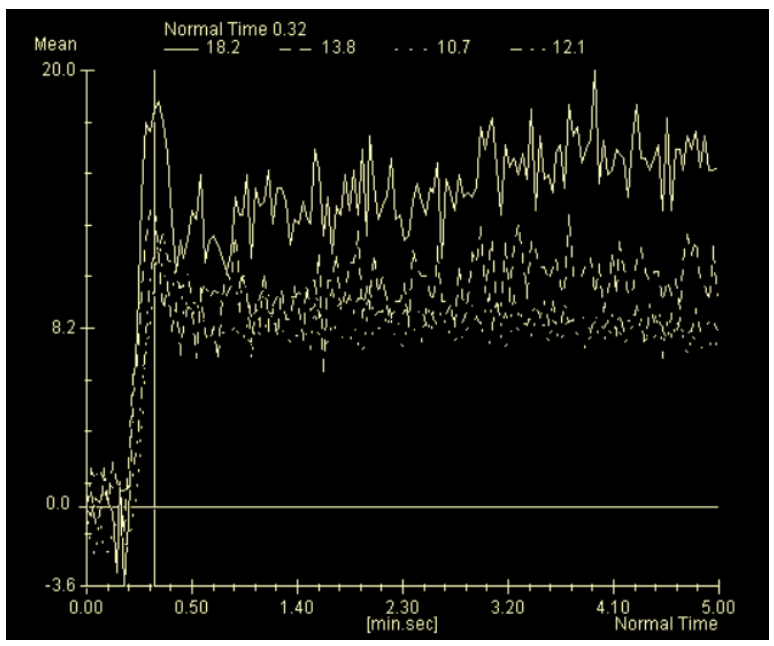

Рис. 3,б.

\section{Рис. 3. Аинамическая контрастная МРТ.}

а - Кривые интенсивности сигнала зАорового Аобровольца при нагрузке. б - Кривые интенсивности сигнала пациента с ХИНК при нагрузке. При нагрузке отмечается появление раннего пика кривой интенсивности перфрузии в обеих группах.

тов с ХИНК и здоровых добровольцев (О[-5; 5 процентили] vs [2,5; 10 процентили], $\mathrm{p}=0,025)$, по отношению $\mathrm{k}$ пациентам с сопутствующей

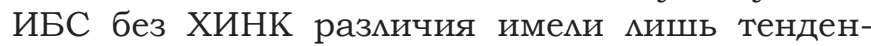
цию к достоверности $(\mathrm{p}=0,05)$.

Время достижения пика перфузии во всех группах составило в среднем 300 с, кривая имела вид восходящей полупараболы (рис. 2, нижние кривые). Обращало на себя внимание изменение формы кривой перфузии при нагрузке в обеих группах - появ ение раннего пика (рис. 3). Время достижения пиковой интенсивности мышечной перфузии при нагрузке в группе пациентов без ХИНК составицо $35,95 \pm 7,18$ с $(37,69 \pm 7,53$ с и $33,13 \pm 5,94$ с в группах пациентов с ИБС и здоровых добровоцьцев соответственно), в группе пациентов с

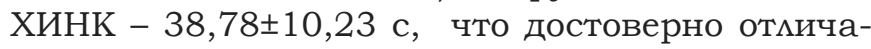
мось от показателей покоя дия всех групп $(\mathrm{p}<0,0001)$, но не различалось между собой 
( $>0,05)$.

\section{Обсуждение.}

В данном исследовании был проведен анализ данных, полученных при помощи динамической контрастной МРТ у сопоставимых по полу, возрасту и сопутствующим заболеваниям пациентов с ХИНК и без, а также здоровых добровольцев.

При физической нагрузке в норме происходит увеличение тканевой перфузии за счет усиления притока крови по магистральным артериям, что проявляется уменьшением времени достижения пиковой интенсивности кровотока, что и бымо продемонстрировано в группе пациентов без ХИНК, где достоверный прирост перфузии при нагрузке сопровождался уменьшением времени достижения пика кровотока. Среди пациентов с ИБС без ХИНК также наблюдался значимый прирост пиковой перфузии при нагрузке, тогда как в группе здоровых добровольцев прирост оказался недостоверным. Отсутствие значимого прироста мышечной перфузии при нагрузке в группе здоровых добровольцев, вероятно, связано с недостаточным уровнем интенсивности нагрузки для данной группы испытуемых, а также с небольшим объемом выборки.

Среди пациентов с облитерирующим атеросклерозом артерий нижних конечностей в ответ на нагрузку не выявлено уменьшения времени достижения пиковой интенсивности артериального кровотока, что обусловлено поражением магистральных артерий. В то же время, без увеличения степени артериального кровотока значимо возрастает тканевая перфу-

\section{Список аитературы:}

1. Criqui M.H., Fronek A., Barrett-Connor E. et al. The prevalence of peripheral arterial disease in a defined population. Circulation. 1985; 71 (3): 510-551.

2. Hiatt W.R., Hoag S., Hamman R.F. Effect of diagnostic criteria on the prevalence of peripheral arterial disease. The San Luis Valley Diabetes Study. Circulation. 1995; 91 (5): 1472-1479.

3. Рекомендаиии Европейского Общества кардиологов по диагностике и лечению заболеваний периферических артерий. Раииональная Фармакотерапия в Кардиологии. 2012. Приложение №4.

4. Чазов Е.И., Карпов Ю.А. Рациональная фармакотерапия сердечно-сосудистых заболеваний. Руководство для практикуюших врачей. М., Аиттерра. 2014; 2 (44): 747-758.

5. Fowkes F.G., Housley E., Cawood E.H. et al. Eginburgh Artery Study: prevalence of asymptomatic and symptomatic peripheral arterial disease in the general population. Int $J$ Epidemiol. 1991; 20 (2): 384-392.

6. Hirsch A., Criqui M.H., Treat-Jacobson D. et al. Peripheral arterial disease detection, awareness, and treatment in primary care. JAMA. 2001; 286 (11): 1317-1324.

7. Selvin E., Erlinger T.P. Prevalence of and risk factors for peripheral arterial disease in the United States: results from the National Health and Nutrition Examination Survey, 1999-2000. зия, что, вероятнее всего, достигается за счет активации комлатерального кровоснабжения.

Способность динамической контрастной МРТ выделять и отличать пациентов с ХИНК от испытуемых с нормальным кровотоком в нижних конечностях была показана еще в 2004 году [13]. В работах 2007-2013 годов при иссиедовании пациентов с ХИНК и здоровых добровольцев в $67 \%$ случаев наблюдался прирост перфузии на фоне нагрузки в обеих группах, что также было продемонстрировано в данном исследовании. Метод доказал свою способность отличать больных периферическим атеросклерозом от здоровых, что было подтверждено бомее поздними исследованиями [13, 14]. Впоследствии было показано, что показатель мышечной перфузии при нагрузке в группе пациентов с ХИНК и без неё не только достоверно отАичался, но и хорошо воспроизводим [16].

\section{Заключение.}

Динамическая контрастная МРТ - перспективный неинвазивный метод, при помощи которого возможно выявить изменение мышечной перфузии в ответ на нагрузку у пациентов с хронической ишемией нижних конечностей, что позволяет косвенно судить о степени выраженности комлатерального кровообращения. Метод может быть использован дия оценки эффективности разцичных видов консервативной терапии, направценных на стимуляцию роста и/или развития комлатеральных сосудов в ишемизированной мышце.

Circulation. 2004; 110 (6): 738-743.

8. Norgren L., Hiatt W.R., Dormandy J.A. et al. Inter-Society Consensus for the Management of Peripheral Arterial Disease (TASC II). Eur J Vasc Endovasc Surg. 2007; 33 (1): 1-75.

9. Стразденъ Е.Ю., Шария М.А., Тарарак Э.М., Устюжанин Д.В. Применение магнитно-резонансной томографии в определении стабильности атеросклеротической бляшки. REJR. 2013; 3 (1): 57-61.

10. Синкевич Н.С., Талиикий К.А., Стукалова О.В., Карпов Ю.А. Магнитно-резонансная томография в диагностике и оценке эффрективности лечения хронической ишемии нижних конечностей. Кардиологический вестник. 2014; 4: 7885.

11. Yanping L., Mohning K., Hradil V. et al. Evaluation of tissue perfusion in a rat model of hind-limb Muscle Ischemia Using Dynamic Contrast-Enhanced Magnetic Resonance Imaging. J Magn Reson Imaging. 2002; 16 (3): 277-283.

12. Heymann M.A., Payne B.D., Hoffman J.I., Rudolph A.M. Blood flow measurements with radionuclide-labeled particles. Prog Cardiovasc Dis. 1977; 20 (1): 55-79.

13. Leppek R., Hoos O., Sattler A. et al. MR-Imaging of lower leg muscle perfusion. Herz. 2004; 29 (1): 32-46.

14. Isbell D., Epstein F., Zhong X. et al. Calf Muscle Perfusion at 


\section{RUSSIAN ELECTRONIC JOURNAL OF RADIOLOGY}

Peak Exercise in Peripheral Arterial Disease: Measurement by First-Pass Contrast-Enhanced Magnetic Resonance Imaging. J Magn Reson Imaging. 2007; 25 (5): 1013-1020.

15. Anderson J.D., Epstein F., Meyer C. et al. Multifactorial Determinants of Functional Capacity in Peripheral Arterial Disease Uncoupling of Calf Muscle Perfusion and Metabolism. JACC.

\section{References:}

1. Criqui M.H., Fronek A., Barrett-Connor E. et al. The prevalence of peripheral arterial disease in a defined population. Circulation. 1985; 71 (3): 510-551.

2. Hiatt W.R., Hoag S., Hamman R.F. Effect of diagnostic criteria on the prevalence of peripheral arterial disease. The San Luis Valley Diabetes Study. Circulation. 1995; 91 (5): 1472-1479.

3. ESC Guidelines on Peripheral Artery Diseases. Rational Pharmacotherapy in Cardiology. 2012. Supplement №4 (in Russian).

4. Chazov E.I., Karpov Yu.A. Rationale For drug therapy of cardiovascular diseases. A guidebook for medical practitioners. $M$., Littera. 2014; 2 (44): 747-758 (in Russian).

5. Fowkes F.G., Housley E., Cawood E.H. et al. Eginburgh Artery Study: prevalence of asymptomatic and symptomatic peripheral arterial disease in the general population. Int $J$ Epidemiol. 1991; 20 (2): 384-392.

6. Hirsch A., Criqui M.H., Treat-Jacobson D. et al. Peripheral arterial disease detection, awareness, and treatment in primary care. JAMA. 2001; 286 (11): 1317-1324.

7. Selvin E., Erlinger T.P. Prevalence of and risk factors for peripheral arterial disease in the United States: results from the National Health and Nutrition Examination Survey, 1999-2000. Circulation. 2004; 110 (6): 738-743.

8. Norgren L., Hiatt W.R., Dormandy J.A. et al. Inter-Society Consensus for the Management of Peripheral Arterial Disease (TASC II). Eur J Vasc Endovasc Surg. 2007; 33 (1): 1-75.

9. Strazden E.YU., Shariya M.A., Tararak E.M., Ustyuzhanin D.V. Application of magnetic resonance imaging in determining
2009; 54 (7): P.628-635.

16. Jiji R.S., Pollak A.W., Epstein F. et al. Reproducibility of rest and exercise stress contrast-enhanced calf perfusion magnetic resonance imaging in peripheral arterial disease. Journal of Cardiovascular Magnetic Resonance. 2013; 15 (14) doi: 10.1186/1532-429X-15-14.

of atherosclerotic plaque stability. REJR. 2013; 3 (1): 57-61 (in Russian).

10. Sinkevich N.S., Talitskiy K.A., Stukalova O.V., Karpov Y.A. Diagnostic and therapy efficiency evaluation of chronic limb ischemia performed by magnetic resonance tomography. Kardiologicheskij Vestnik. 2014; 4: 78-85 (in Russian).

11. Yanping L., Mohning K., Hradil V. et al. Evaluation of tissue perfusion in a rat model of hind-limb Muscle Ischemia Using Dynamic Contrast-Enhanced Magnetic Resonance Imaging. J Magn Reson Imaging. 2002; 16 (3): 277-283.

12. Heymann M.A., Payne B.D., Hoffman J.I., Rudolph A.M. Blood flow measurements with radionuclide-labeled particles. Prog Cardiovasc Dis. 1977; 20 (1): 55-79.

13. Leppek R., Hoos O., Sattler A. et al. MR-Imaging of lower leg muscle perfusion. Herz. 2004; 29 (1): 32-46.

14. Isbell D., Epstein F., Zhong X. et al. Calf Muscle Perfusion at Peak Exercise in Peripheral Arterial Disease: Measurement by First-Pass Contrast-Enhanced Magnetic Resonance Imaging. J Magn Reson Imaging. 2007; 25 (5): 1013-1020.

15. Anderson J.D., Epstein F., Meyer C. et al. Multifactorial Determinants of Functional Capacity in Peripheral Arterial Disease Uncoupling of Calf Muscle Perfusion and Metabolism. JACC. 2009; 54 (7): P.628-635.

16. Jiji R.S., Pollak A.W., Epstein F. et al. Reproducibility of rest and exercise stress contrast-enhanced calf perfusion magnetic resonance imaging in peripheral arterial disease. Journal of Cardiovascular Magnetic Resonance. 2013; 15 (14) doi: 10.1186/1532-429X-15-14. 